\title{
Existence of Microplastics in Indonesia's Surface Water: A Review
}

\author{
Firdaus Ali ${ }^{1 *}$, Khalidah Nurul Azmi ${ }^{2}$, Madina Rain Firdaus ${ }^{2}$ \\ ${ }^{1}$ Department of Civil Engineering, \\ Universitas Indonesia, Depok, 16424, INDONESIA \\ ${ }^{2}$ Indonesia Water Institute, Rukan Tanjung Barat Indah No. F-02, South Jakarta, 12530, INDONESIA \\ *Corresponding Author
}

DOI: https://doi.org/10.30880/ijie.2021.13.03.012

Received 20 December 2020; Accepted 01 May 2021; Available online 06 June 2021

\begin{abstract}
Plastic waste is often being an issue that needs to be overcome since mostly plastic waste ends up in the environment. Some studies stated that plastic waste found in the marine environment are mostly sourced from the land which transported along the river systems. It is nearly impossible for nature to completely breakdown plastic waste, regarding its durability and resistance to degradation. Small fragment resulted from the slowly breakdown of plastic waste is an emerging contaminant in water environment called as microplastic. This study is conducted as a short review of microplastics existence on the surface water in Indonesia, particularly on the Citarum River as the most polluted river in the world. Besides, only few papers regarding microplastic occurrence on the surface water in Indonesia that have been published, which mostly focuses on Citarum River. It is known that microplastic tend to persist in water and has possible risks to the living organisms. Hence, managing microplastic pollution is needed which can be in the form of management strategy and treatment technologies used to remove microplastics from water.
\end{abstract}

Keywords: Microplastic, surface water, water environment

\section{Introduction}

Nowadays, plastic waste is often being an issue that needs to be overcome. Plastic material contained almost in every product, which human use them daily without further concern about the waste that have been generated. From all plastic waste ever generated, only $9 \%$ the waste that has been recycled, $12 \%$ the waste that has been incinerated, whereas the rest $79 \%$ has piled-up in the final disposal sites or ended-up in the environment [1]. Plastic waste is more possible to generate at product manufacturing sites and densely populated area such as urban centers, where the area in coastal or near rivers [2]. These sources more probable leading to the phenomenon of ocean pollution. Whether in river, ocean, or on land, it is known that plastic waste tends to persist in these environments for ages [1]. It is almost impossible for environment to entirely breakdown plastic waste, due to the resistance properties of this material.

Most of plastics do not biodegrade, but instead photodegrade, meaning it slowly break down into small fragment called as microplastic [3]. Microplastic known as an emerging contaminant in water environment. Due to its small size, microplastic tend to drift in water, which can eventually end up in marine organisms [4]. However, about $80 \%$ of plastic waste found in the marine environment are sourced from the land [5], which transported via river. Rivers as transport pathways of plastic debris, with its dynamic system can either retain or transport microplastic [6]. Studies about the occurrence of microplastics in river or surface water such as in urban areas [7], [8] have been conducted recently, and reported that the major type of collected microplastics was fiber. Similar study also has been conducted in 
surface water and wastewater of urban rivers [9], reported that microplastics collected was predominance in the form of fibers across different systems of urban water. Fibers and fragments known as secondary microplastic coming from sewage effluent or surface runoff [10]. It can be said that surface water or river in urban areas has a greater microplastics contribution from secondary sources, rather than fragmentation and degradation of plastic litter.

Indonesia, a country with a long coastal line, known as the second top in the world that contribute the greatest amount of plastic waste in the marine environment [11]. To overcome this complex issue, Indonesia has established the National Action Plan (NAP) which committed to reduce plastic waste nationally in the amount of $70 \%$ by 2025 [12]. It is known that plastic is easily distributed, and its distribution can be started from upstream, middle stream, to the downstream of river. The fluvial system in the region of Indonesia is directed to coastal area, which the flows through residential, industrial, and agricultural areas. High population in urban areas and a densely populated in the riverbank, along with inadequate management of plastic waste in Indonesia, it is possible that microplastics occur in the surface water or river as receiving water body. The contaminant could be ingested by living organisms, such as invertebrates and fish, that might directly expose them to other pollutants [13], [14]. Microplastic could pose chronic toxicity effects on the living organisms, which make this contaminant as an important issue for its long-term exposure [15].

The goal of this study is to provide a short review about the existence of microplastics on the surface water in Indonesia. The surface water that will be reviewed based on most relevant studies that have been conducted, which also supported with other literatures. Managing microplastic pollution is needed which can be in the form of management strategy and treatment technologies used to remove microplastics from water.

\section{Sources and Transport of Microplastic into Water}

\subsection{Overview of Plastic}

Plastic material consists of long polymer chains, which are made by a reaction between small organic molecules or monomers. Generally, plastic is divided into two categories, which are thermoplastics and thermoset plastic. Plastic produced globally is dominated by six types: polypropylene (PP), polyethylene (PE), polystyrene (PS), polyvinyl chloride (PVC), polyethylene terephthalate (PET), and polyurethane (PUR) [16]. The five types (PP, PE, PS, PVC, and PET) are classified as thermoplastics which known as plastic that can be recycled, while PUR is classified as thermoset plastics. It is explained that PP usually used in sweet and snack wrappers, food packaging, automotive parts; PE used in plastic bags, toys, shampoo bottles; PS used in plastic cups, food containers (Styrofoam), eyeglasses frames; PVC used in pipes, cable insulation, window frames; PET used for bottles of water, other beverages, and cleaners; while PUR used in building insulating foams, pillows, mattresses [17].

The amount of global plastic production in 2015 was calculated approximately at 381 million tons, while the plastic production including additives (i.e., colorants, plasticizers, stabilizers filers, reinforcements) was 407 million tons [18]. The predictions of global plastic production are stated it will be in double amount by 2025 , while by 2050 it will be more than triple, considering the current consumption, population growth, and waste disposal habits [19]. The non-fiber (PE, PP, PVC, PET, PUR, and PS) and fiber (polyester and acrylic) plastic production account for $92 \%$ of total plastics ever made [18]. Regarding its size, plastic can be divided into five categories: nano-plastic $(<1 \mu \mathrm{m})$ [16], micro-plastic $(5 \mathrm{~mm}-1 \mu \mathrm{m})$, meso-plastic $(20-5 \mathrm{~mm})$, macro-plastic $(>20 \mathrm{~mm})$, and mega-plastic $(>100 \mathrm{~mm})$ [20]. It is stated that intentional microplastic production represents less than $0.1 \%$ of total plastic production [17].

\subsection{Mismanaged Plastic Waste}

The mass production of plastic products has increased globally since 1950s, and the litter has accumulated in environments, from terrestrial, shorelines, ocean, to the deep sea. Many studies have been conducted and found that plastic waste accumulated in environments, even in most remote islands. Most plastics material that manufactured, such as PP and PE, have a relatively short lifetime during the use which rapidly piled-up in the waste disposal sites, while plastic materials applied in the building construction, such as PVC, have much longer lifetime [16]. In the last four decades, it is stated that the accumulation of macro-plastics and microplastics has increased consistently on shores and in sediments [20]. Their properties (e.g., inexpensive, lightweight, durable) have made the service life of plastic mostly in single use and then to be thrown away. This condition leading to the mismanagement of global plastic waste.

Mismanaged plastic waste is plastic that is littered or inadequately dumped, which is not supported by a proper management [11]. It is explained that mismanaged plastic waste could end up in the ocean, which transported by the fluvial or river systems. The study tried to estimate the plastics waste inputs from land into ocean, related to the data on population density, economic status, and solid waste generation [11]. From the study, plastic waste generation in 2010 was estimated to be 275 million metric tons by the coastal countries which account for $93 \%$ of global population, while plastic waste that enter the ocean was in the range of 4.8 to 12.7 million metric tons. Countries which contribute to the largest mass of plastic waste is greatly determined by condition of solid waste management and total population in the country's area. Here, Indonesia is stated as the second top in the world that contribute the largest mass of plastic waste found in the marine environment. The amount of plastic waste that carried by fluvial or river systems also depend on the characteristic of local watersheds. 


\subsection{Type and Source of Microplastic}

In defining microplastic, mostly literatures focus on its composition and size. The composition of microplastic is not standardized [17], while the size of microplastic is described in the range of $5 \mathrm{~mm}-1 \mu \mathrm{m}$. The determination size of microplastic is considering that it could be easily ingested by living organisms, such as biota, which might pose them to more threats [16]. Besides, it is to simplify the sampling and analyzing method used for this contaminant to be studied [17].

Generally, there are two categories of microplastic, which are primary microplastic and secondary microplastic. Primary microplastic known as plastic that is manufactured in micro-sized product, while secondary microplastic is resulted by larger plastic item when in breakdown state [16]. The category is useful as distinction to specify possible sources and arrange mitigation steps in reducing microplastics pollution. Microbeads in cosmetics or personal care products, generally as exfoliants, the plastic pellets used in product manufacturing [2], and "scrubbers" to blast clean surfaces in industry [16], all of them categorized as primary microplastic. Whereas the breakdown state of larger plastic item resulting secondary microplastic, through fragmentation or weathering process from products such as bottles, clothes or textiles, bags, paint, and tires [16], [17], either during the use of products or once they release into the environment.

Secondary microplastics are found in a far more abundant in the oceans [20] rather than primary microplastics. This type of microplastic includes textile fiber fragments released during laundering of clothing, and fragments of mulch films resulted from agricultural field. It is rational to state that mostly secondary microplastics generated on land could eventually washed away to the ocean [2]. However, the weathering process of plastic waste accumulated in the coastal area [5] is possibly as the predominant source of secondary microplastics [21].

\subsection{Ways of Microplastic enter the Water Environment (Surface Water)}

Possible sources and transport of microplastic into surface water as water environment included runoff from landbased sources; wastewater effluent; industrial effluent; and fragmentation and degradation of macro-plastic. The ways of microplastic enter the environment, including transport and distribution, will be depending on its inherent properties such as density, size, and shape [17]. It is stated that common plastic consumed has a density in the range of 0.85 to $1.41 \mathrm{~g} / \mathrm{cm}^{3}$ [14]. Given the density of freshwater, $1 \mathrm{~g} / \mathrm{cm}^{3}$, it is possible that microplastic will sink or will float in the water. This contaminant has been entered into freshwater environment, particularly the surface waters [17] as water body. There is a general tendency to observe the microplastics occurrence in the surface water, which would be at higher concentrations in near densely populated urban areas [7]-[9]. A recent study has estimated the loads of plastic litter in the different environmental compartments [22]. It is stated that surface waters are the key vectors for transporting microplastic, regarding this environment are generally closer to the sources of plastic rather than marine. About $70-80 \%$ of plastic debris found in marine are transported to the sea via rivers as the conduits, with predominant sources from mishandled plastic debris, agricultural land, and effluent of wastewater treatment plant [23].

A study suggested that the significant input of land-based sources is from road surfaces runoff [24]. Another important land-based sources of microplastic is textiles activities, through washing and wear-and-tear [25], [26]. Agricultural runoff also recognized to be a potential source, regarding the application of sewage sludge (as fertilizer) and agricultural mulch in the land [23]. The runoff could transport microplastic to the lakes, rivers, and eventually reach the ocean [13]. Other than that, fragmentation, and degradation of macro-plastic litter in urban areas can generate the abundance of microplastics, when the litter enter surface water. Plastic product dumping activities, surfaces runoff, and urban or municipal wastewater are the significant proportions of plastic debris found in the surface water [27]. It is known that once macro-plastic debris enter the surface water, chemical changes may occur due to UV radiation along with high temperatures, which making the plastic more sensitive to be degraded and fragmentated [17].

Wastewater effluent has been identified as one of the main sources of microplastic pollution in the surface water [24]. A study has conducted the measurement of microplastics at upstream and downstream area of the effluent with different catchments, stated that all the results show an increase amount of microplastics [28]. Microplastic in type of fibers have been identified in the effluent from sewage treatment plants [29], which possibly released through washing clothes activities. Wastewater discharge from industrial is also recognized to be the source of microplastic pollution, which a study has been identified pre-production pellets at a river in Los Angeles basin, Great Lakes, and Danube River [14]. The pellets could be ingested by aquatic organisms and may directly pose them to other pollutants.

\section{Microplastics Occurrence in Indonesia's Surface Water}

\subsection{Mismanaged Plastic Waste in Indonesia}

As described earlier, Indonesia has status as the second top in the world that contribute the largest amount of marine plastic waste. This is based on a conducted study in 2010, which estimated the mass of plastic waste generated from terrestrial or land to the sea [11]. Among 192 coastal countries, 20 countries are identified as the largest mass contribution of mismanaged plastic waste in the marine environment. The mismanaged plastic waste in each coastal country is estimated by population size within radius of $50 \mathrm{~km}$ from the coastal area. Other main consideration is the 
condition of solid waste management in the considered country. The waste generation rate in Indonesia is estimated about $0.52 \mathrm{~kg} /$ person-per-day (plastic waste accounts for $11 \%$ ), with $83 \%$ of that total is mismanaged. With a coastal population of 187.2 million, the study calculated that 3.22 million metric tons/year of mismanaged plastic waste is generated, and this resulting plastic marine debris in the range of 0.48-1.29 million metric tons/year for Indonesia.

Mismanaged plastic waste, which leading to the marine pollution, have effect on the ecosystems. Scientists have stated that marine pollution could harmful its biota life, ecosystems, and also humans [30]. Given the mismanaged plastic waste could eventually reach the ocean via rivers or stormwater drains, hence microplastics (whether from primary or secondary sources) may occur and also abundant in freshwater system as the water body before the ocean. It is stated that oceans become the final sink for the global plastic and microplastic waste that are mismanaged, which received through freshwater systems (primarily surface waters) on the lands [17]. Meanwhile, the amount of plastic waste that carried by river systems is known depend on the local watershed characteristics [11].

\subsection{As A Surface Water and Receiving Water Body: Citarum River}

The river systems in Indonesia play important roles for the socio-economic life, especially in Java as the most populated island. One of the main rivers that supports life on Java, particularly West Java, is the well-known Citarum River [31]. This river is the longest and largest river in West Java, with the flows along $297 \mathrm{~km}$ from the upstream (Wayang Mountain, Bandung Regency) to the downstream (Muara Gembong, Bekasi Regency), before ending at Java Sea [32]. Specifically, Citarum River is passing 9 regencies and 3 cities: West Bandung Regency, Bandung Regency, Subang Regency, Purwakarta Regency, Karawang Regency, Sumedang Regency, Cianjur Regency, Bekasi Regency, Indramayu Regency, Bandung City, Bekasi City, and Cimahi City. Water resource provided by the Citarum River generally used as a source of freshwater (also supplies for $80 \%$ of Jakarta's residents), agricultural irrigation, fisheries, hydropower, and water supply for industries [33].

According to Presidential Decree No. 12/2012 on River Basin Territories, the Citarum river basin consists of 19 watershed areas. Citarum river basin has a total area of $13,000 \mathrm{~km} 2$, serves \pm 600 textile factories and twenty-eight million people [34]. Other industries served by Citarum river basin include food and beverage, metal, and pharmaceutical industries. However, Citarum River has status as the most polluted river in the world. Industrial textiles have a great contribute to the toxic pollution of rivers in West Java. The textile industries account for 68\% from total industries that located in the upstream area of Citarum River [31]. Fig. 1 depicted the occurred pollution on the upper Citarum River, which caused by textile industries with noticeable difference color on the surface water [35].

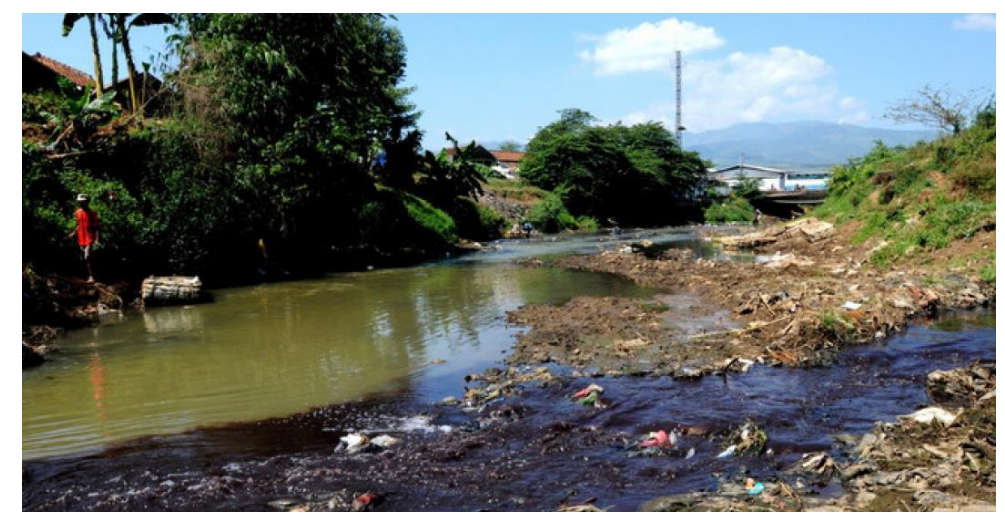

Fig. 1 - River pollution on the upper Citarum [35]

Other main contributors of surface water pollution on the upper Citarum are domestic (contributes 64\%), agricultural, and livestock activities [32]. The large percentage of domestic is due to daily activities, such as bathing, laundry, and cooking, for many people that are supported by Citarum River. This river has potential to be polluted by microplastics, since the occurrence is mostly related to the population density [4] along with their activities. The declining quality of Citarum River has been an obvious concern, with considering its geographical scale, industrial and agricultural use, the number of people depend on the river for their daily needs [34], and people's behavior that still dispose their waste directly into the river.

\subsection{Studies Reported the Existence of Microplastics in Indonesia's Surface Water}

In Indonesia, studies about the presence of microplastics have been conducted mostly in coastal areas and its sediments. This regarding the status of Indonesia as the second top in the world that contribute the largest amount of marine plastic waste. Marine plastic debris are mostly derived from lands, which the rivers or surface waters considered as the main transport pathways for microplastic [13]. However, only few studies in Indonesia that have been conducted about the existence of microplastics primarily in surface water or river as receiving water body. It has been observed 
that those few studies have been conducted mostly in Citarum River, regarding its status as the most polluted river in the world. Thus, studies below briefly reported the existence of microplastics in Citarum River.

A study measured microplastic distribution in surface water of one of the tributaries in Citarum River [36]. This tributary, Ciwalengke River, is located in the area of upper Citarum River. The river located along the densely populated settlements which also dominated with textile industries. The study collected surface water samples from ten locations using grab sampling method, $45 \mathrm{~cm}$ from the surface. Microplastic separation in water samples was done by Whatman GF/C glass microfiber filter $1.2 \mu \mathrm{m}$, then it was dried in oven at $105^{\circ} \mathrm{C}$ for 30 minutes. The observation of filtered material was done by binocular microscope to identify the microplastic particles and categorize them by shape and size. Microplastic particles reported from surface water samples were in the average concentration of $5850 \pm 3280$ particles $/ \mathrm{m}^{3}$. It was found that microplastic distribution was dominated by fiber. Other than that, the particles of microplastic were found more abundant in the size of 50-100 $\mu \mathrm{m}$. Raman spectroscopy characterization was used to analyze the microplastic suspected particles, which the result indicated that the types were polyester and nylon (polyamide). Based on the study, microplastics abundance is more likely to generate from the wear-and tear and washing activities in textile industries and also the laundry activities by local residents. It is known that the use of detergent in washing process can generate more fibers released from the cloth.

A study about the abundance and composition of macroplastic and microplastic in the estuary water of Citarum River, which located at Muara Gembong, has been conducted [37]. Along with its densely populated settlements, the river is often used as final disposal site by local residents. However, this study stated the result in combining for macroplastic and microplastic particles as plastic flakes. This study aims to give an early information about plastic flakes pollution in Citarum River, particularly in the estuary water. Water sampling was carried out by plankton net (mesh $30 \mu \mathrm{m}$ ) in two sampling stations, which each station divided into three substations. For each substation, water sampling was done in three water depths: surface, $50 \mathrm{~cm}$, and $100 \mathrm{~cm}$. Water sample filtration was done by using graded filter (mesh $4 \mathrm{~mm}, 2 \mathrm{~mm}, 1 \mathrm{~mm}$, and $500 \mu \mathrm{m}$ ). Particle in size of $<5 \mathrm{~mm}$ determined as microplastic, while particle in size of $>5 \mathrm{~mm}$ determined as macroplastic. Analysis of macroplastic and microplastic was carried out by binocular microscope supported with Sedgwick Rafter Counter (SRC) and micrometer. The abundance of macroplastic and microplastic in water samples were found in the range of $874-1332$ particles $/ \mathrm{m}^{3}$. Fiber was found as the predominant type of macroplastic and microplastic in the water surface samples. Fiber was suspected more likely to generate from laundering activities and fishing net used in fisheries. Other than that, the size of macroplastic and microplastic was found dominant in the range of 100-1000 $\mu \mathrm{m}$. The types of polymer were analyzed by using FT-IR. Before the analysis, sample was filtered using filter paper Whatman-42, and then the filter paper containing plastic particles was dried in oven at $40^{\circ} \mathrm{C}$ for 30 minutes. It was found that types of polymer in microplastic samples were nylon and polystyrene (PS). Nylon usually used in food packaging, toothbrush, refrigerator, fishing line and net. Meanwhile, PS usually used in foam packaging, food container, plastic cutlery, and clothing fiber.

Meanwhile, studies reported the presence of microplastics in the downstream area of Citarum River have been conducted recently [38], [39]. Citarum River's downstream in this study is located at Muara Gembong, Bekasi Regency. The studies aimed to identify microplastic concentration in the water of Citarum River's downstream. Water samples were taken by a manta trawl (mesh $125 \mu \mathrm{m}$ ) in 3 segments of the river, sample that held with a mesh were dried in oven at $60^{\circ} \mathrm{C}$ over $24 \mathrm{~h}$, and then used the Fenton Oxidation method $\left(\mathrm{Fe}\right.$ and $\left.\mathrm{H}_{2} \mathrm{O}_{2}\right)$ to remove and clean the organic material at $75^{\circ} \mathrm{C}$. Suspected particles then were placed into the petri dish for microplastics visualization. Microplastic concentration reported from water samples were in the average of $0.0574 \pm 0.025 \mathrm{particles} / \mathrm{m}^{3}$. The visualization was done by a microscope (ImageJ software) in determining the shape and size of microplastic. Fragments was found as the predominant shape in the water samples. It is known from the study that microplastics abundance is more likely to generate from daily used plastics which are widely used by the residents. The microplastic particles were found dominant in the size of $1000-5000 \mu \mathrm{m}$. This large size of microplastics is due to the use of manta trawl, which is known to be more effective in grabbing larger size of microplastics rather than other methods. In determining the type of plastic polymer, a Fourier-transform infrared (FT-IR) spectroscopy was used in the study. It was found that the predominant types were polyethylene (PE) and polypropylene (PP), which can be speculated that sources of these polymers are from residential areas and industries.

All reported studies about the existence of microplastics in Citarum River is summarized in Table 1. The abundance of microplastics in Citarum River were in different amounts due to many factors, such as the sampling time and locations, sampling method used (include water depths for sampling), low and high tide of the river, runoff condition, and activities that affect the segments of the river. The activities that affect segments of the river can be related to the local watershed characteristics. Based on those few reported studies, it can be correlated that industries, densely populated settlements, and fisheries are the sources which more likely to generate microplastics into Citarum River. Fiber and fragment were found as the predominant shapes in microplastic samples based on those few reported studies. These shapes can be resulted from fragmentation or breakdown of larger plastic items, thus microplastic particles found at Citarum River can be mostly categorized as secondary microplastics.

It can be speculated that fiber was released from laundering activities by the residents, washing process from textile industries, and fishing net used in the fisheries. Fiber is stated as an important source of microplastics in the surface water [29]. Meanwhile, particle shape of fragment can be speculated from the breakdown of daily used plastics 
by the residents. A study stated that categories of fibers (particles of fishing line, fishing nets, and from synthetic textiles) and fragments (from the breakdown of larger plastic items) are actually a morphology-based rather than source-based [40]. The study also stated that it would be somewhat objective for attributing a source of each particle due to the limited information. Given the occurrence and abundance of microplastics in Citarum River, the activities that affect the river should be adequately managed. Furthermore, the occurrence and abundance of microplastics in Citarum River could help to illustrate the possible risks to the residents and its surrounding area, which can also be a reference for other similar rivers in Indonesia.

Table 1 - Microplastics existence in Citarum River from different studies

\begin{tabular}{|c|c|c|c|c|c|}
\hline Location & $\begin{array}{c}\text { Results } \\
\text { reported } \\
\left(\text { particles } / \mathbf{m}^{3}\right)\end{array}$ & $\begin{array}{c}\text { Abundant } \\
\text { particle size } \\
(\mu \mathrm{m})\end{array}$ & $\begin{array}{c}\text { Predominant } \\
\text { particle } \\
\text { shape }\end{array}$ & $\begin{array}{c}\text { Predominant } \\
\text { polymer } \\
\text { type }\end{array}$ & Study \\
\hline $\begin{array}{l}\text { Citarum River's upper } \\
\text { tributary: Ciwalengke River }\end{array}$ & $\begin{array}{c}\text { Average: } \\
5850 \pm 3280\end{array}$ & $50-100$ & Fiber & Polyester, nylon & {$[36]$} \\
\hline $\begin{array}{l}\text { Citarum River's estuary } \\
\text { (Muara Gembong) }\end{array}$ & $874-1332^{\mathrm{a}}$ & $100-1000^{\mathrm{a}}$ & Fiber $^{\mathrm{a}}$ & Nylon, PS & [37] \\
\hline $\begin{array}{l}\text { Citarum River's downstream } \\
\text { (Muara Gembong) }\end{array}$ & $\begin{array}{c}\text { Average: } \\
0.0574 \pm \\
0.025\end{array}$ & $1000-5000$ & Fragment & PE, PP & $\begin{array}{l}{[38],} \\
{[39]}\end{array}$ \\
\hline
\end{tabular}

${ }^{a}$ Study stated the result as plastic flakes (macroplastic and microplastic)

Actually, methods used for sampling and analysis of microplastics on environmental samples are various and not standardized. Three principles in sampling and analysis of microplastics: sampling; sample extraction and isolation; identification, characterization, and quantification. Methods used for sampling and preparation are determined by the type of samples that will be taken (e.g., water, sediment). Sampling for water can be carried out by trawl nets (typically $300 \mu \mathrm{m})$ across the water surface, or by collecting the samples which then the particles need to be extracted. Purification of the sample can be done by filtration, followed by density separation as an extraction process. Chemical or enzymatic methods may be used in removing the organic or inorganic materials. Particles suspected as microplastics may be visually sorted before microscopic quantification. Three different approaches in determining the size and composition of plastic particles are spectroscopic, thermo-analytical, and chemical (conventional method). Spectroscopic (e.g., FTIR, Raman spectroscopy) can be used to identify polymers chemical structure, while thermoanalytical methods (e.g. pyrolysis-gas chromatography/mass spectrometry or GC/MS) tend to require larger particle masses and can be used to analyze the specific decomposition products of individual polymer. Software packages can also be used to support both in tagging and spectroscopic studies of the particles [17].

\section{Managing Microplastic Pollution in Water Environment}

The accumulation of plastics and microplastics in water environment has been one important issue. Microplastic known as an emerging contaminant in water environment, which can be resulted from the breakdown of larger plastic item. Due to its small size, microplastic could be ingested along the food web, thus this contaminant is of a special concern [13]. This contaminant could cause harmful effects on living organisms and humans through entanglement and ingestion [15]. Hence, plastic and microplastic pollution in the water environment should be managed and controlled. Understanding the microplastic categories can be useful to identify its possible sources and arrange the mitigation steps related to microplastic pollution [17].

Given the status as the second top in the world that contribute the largest mass of marine plastic waste, Indonesia is committed to reduce plastic waste nationally up to $70 \%$ by 2025 as stated in Presidential Regulation No. 83/2018, through the NAP. NAP consists of five main points, which are i) improving behavioral change; ii) reducing land-based leakage; iii) reducing sea-based leakage; iv) reducing plastics production and use; and v) enhancing funding mechanisms, policy reform, and law enforcement [30]. The effectiveness of reuse, recycle, and solid waste management are the key factors affecting the amount of plastic waste that reach the ocean [16]. Reducing land-based leakage is known to be the significant step to manage plastic and microplastic pollution in water environment. Marine plastic debris are mostly derived from land-based sources, including surface waters [13], thus the activities that affect surface waters should be adequately managed.

Installing and optimizing wastewater treatment for households and industries could be one of the solutions to reduce microplastics pollution in surface water as receiving water body. Microplastics can be removed by $90 \%$ with secondary, tertiary, or reverse osmosis treatment, relative to its concentration in primary treated effluent [41]. Meanwhile, with tertiary treatment (e.g., rapid sand filtration, membrane bioreactors, air flotation) can remove microplastics by $95-99.9 \%$ [42]. Other than that, law enforcement is also an important step to manage plastic and 
microplastic pollution in water environment. As in Citarum River, with its status as the most polluted river in the world, has been an obvious concern for the government of Indonesia to immediately tackle this problem. Hence, the Presidential Regulation No. 15/2018 has been released in order to accelerate the pollution and damage control in Citarum Watershed. It is expected that enhancing law enforcement in the local area can substantially help to reduce microplastic pollution in the water environment.

\section{Conclusion}

Surface waters has potential to be polluted by microplastics, regarding this environment are generally closer to the sources of plastic rather than marine. The occurrence of microplastics is mostly related to the population density along with their activities. As in Citarum River, one of the main rivers in Indonesia, several studies have been found the existence of microplastics in this river. Microplastic particles found at Citarum River can be categorized as secondary microplastics based on the predominant particle shape (fiber, fragment). The activities that affect the river (e.g., households, industries) should be adequately managed, such as through reducing land-based leakage. Installing wastewater treatment and enhancing the law enforcement can help to reduce microplastic pollution in the water environment. However, understanding microplastic category can be useful to identify its possible sources and arrange the mitigation steps related to microplastics pollution.

\section{Acknowledgement}

This research was fully funded by Indonesia Water Institute.

\section{References}

[1] United Nations Environment (2018). Beat Plastic Pollution. https://www.unenvironment.org/interactive/beatplastic-pollution/

[2] Andrady A. L. (2017). The plastic in microplastics: A review. Marine Pollution Bulletin, 119, 12-22

[3] United Nations Environment Programme (2018). Single-Use Plastics: A Roadmap for Sustainability. Nairobi

[4] Cordova M. R., Purwiyanto A. I. S. \& Suteja Y. (2019). Abundance and characteristics of microplastics in the northern coastal water of Surabaya, Indonesia. Marine Pollution Bulletin, 142, 183-188

[5] Andrady A. L. (2011). Microplastics in the marine environment. Marine Pollution Bulletin, 62, 1596-1605

[6] Blair R. M., Waldron S., Phoenix V. \& Gauchotte-Lindsay C. (2017). Micro- and nanoplastic pollution of freshwater and wastewater treatment systems. Springer Science Reviews, 5, 19-30

[7] Wang W., Ndungu A. W., Li Z. \& Wang J. (2017). Microplastics pollution in inland freshwaters of China: A case study in urban surface waters of Wuhan, China. Science of the Total Environment, 575, 1369-1374

[8] Wen X., Du C., Xu P., Zeng G., Huang D., Yin L., Yin Q., Hu L., Wan J., Zhang J., Tan S. \& Deng R. (2018). Microplastic pollution in surface sediments of urban water areas in Changsha, China: Abundance, composition, surface textures. Marine Pollution Bulletin, 136, 414-423

[9] Dris R., Gasperi J., Rocher V., Saad M., Renault N. \& Tassin B. (2015). Microplastic contamination in an urban area: A case study in Greater Paris. Environmental Chemistry, 12, 592-599

[10] Sadri S. S. \& Thompson R. C. (2014). On the quantity and composition of floating plastic debris entering and leaving the Tamar Estuary, Southwest England. Marine Pollution Bulletin, 81, 55-60

[11] Jambeck J. R., Geyer R., Wilcox C., Siegler T. R., Perryman M., Andrady A., Narayan R. \& Law K. L. (2015) Plastic waste inputs from land into the ocean. Marine Pollution, Research Reports, 347(6223), 768-771

[12] Purba N. P., Handyman D. I. W., Pribadi T. D., Syakti A. D., Pranowo W. S., Harvey A. \& Ihsan Y. N. (2019). Marine debris in Indonesia: A review of research and status. Marine Pollution Bulletin, 146, 134-144

[13] Wagner M., Scherer C., Alvarez-Muñoz D., Brennholt N., Bourrain X., Buchinger S., Fries E., Grosbois C., Klasmeier J., Marti T., Rodriguez-Mozaz S., Urbatzka R., Vethaak A. D., Winther-Nielsen M. \& Reifferscheid G. (2014). Microplastics in freshwater ecosystems: what we know and what we need to know. Environmental Sciences Europe, 26(12), 1-9

[14] Eerkes-Medrano D., Thompson R. C. \& Aldridge D. C. (2015). Microplastics in freshwater systems: A review of the emerging threats, identification of knowledge gaps and prioritisation of research needs, Water Research, 75, 63-82

[15] Li J., Liu H. \& Chen J. P. (2018). Microplastics in freshwater systems: A review on occurrence, environmental effects, and methods for microplastics detection. Water Research, 137, 362-374

[16] GESAMP Joint Group of Experts on the Scientific Aspects of Marine Environmental Protection (2015). Sources, Fate and Effects of Microplastics In the Marine Environment: A Global Assessment. Reports and Studies GESAMP No. 90. International Maritime organization

[17] World Health Organization (2019). Microplastics in Drinking-Water. World Health Organization

[18] Geyer R., Jambeck J. R. \& Law K. L. (2017). Production, use, and fate of all plastics ever made. Science Advances, Research Article, 3, 1-5 
[19] Lusher A. L., Hollman P. C. H. \& Mendoza-Hill J. J. (2017). Microplastics in fisheries and aquaculture: status of knowledge on their occurrence and implications for aquatic organisms and food safety. FAO Fisheries and Aquaculture Technical Paper, No. 615. FAO UN

[20] Barnes D. K. A., Galgani F., Thompson R. C. \& Barlaz M. (2009). Accumulation and fragmentation of plastic debris in global environments. Philosophical Transactions of The Royal Society B, Biological Sciences, 364, 1985-1998

[21] Hidalgo-Ruz V., Gutow L., Thompson R. C. \& Thiel M. (2012). Microplastics in the marine environment: A review of the methods used for identification and quantification. Environmental Science and Technology, 46, 3060-3075

[22] Alimi O. S., Budarz J. F., Hernandez L. M. \& Tufenkji N. (2018). Microplastics and nanoplastics in aquatic environments: aggregation, deposition, and enhanced contaminant transport. Environmental Science and Technology, 52, 1704-1724

[23] Horton A. A., Walton A., Spurgeon D. J., Lahive E. \& Svendsen C. (2017). Microplastics in freshwater and terrestrial environments: Evaluating the current understanding to identify the knowledge gaps and future research priorities. Science of the Total Environment, 586, 127-141

[24] Horton A. (2017). Microplastics in the freshwater environment: A review of current knowledge. Foundation for Water Research

[25] Henry B., Laitala K. \& Klepp I. G. (2019). Microfibres from apparel and home textiles: Pospects for including microplastics in environmental sustainability assessment. Science of the Total Environment, 652, 483-494

[26] Schöpel B. \& Stamminger R. (2019). A comprehensive literature study on microfibres from washing machines. Tenside Surfactants Detergents, 56(2), 94-104

[27] Gasperi J., Dris R., Bonin T., Rocher V. \& Tassin B. (2014). Assessment of floating plastic debris in surface water along the Seine River. Environmental Pollution, 195, 163-166

[28] Kay P., Hiscoe R., Moberley I., Bajic L. \& McKenna N. (2018). Wastewater treatment plants as a source of microplastics in river catchments. Environmental Science and Pollution Research, 25, 20264-20267

[29] Napper I. E. \& Thompson R. C. (2016). Release of synthetic microplastic plastic fibres from domestic washing machines: Effects of fabric type and washing conditions. Marine Pollution Bulletin, 112, 39-45

[30] The Government of the Republic of Indonesia (2017). Indonesia's Plan of Action on Marine Plastic Debris $2017-$ 2025. Executive Summary. Deputy for Human Resources, Science, Technology, and Maritime Culture

[31] Asian Development Bank (2016). Indonesia Country Water Assessment. Asian Development Bank

[32] Husein D. S., Nurasa H., Adiwisastra J. \& Myrna R. (2017). Coordination on integrated Citarum water resources management investment program (ICWRMIP) in Bandung regency. Advances in Social Science, Education and Humanities Research, 141, 94-99

[33] Cita-Citarum (2011). The Integrated Management Plan of Citarum River Basin 2010-2025 (Rencana Penanganan Terpadu Wilayah Sungai Citarum 2010-2025). Indonesia

[34] Cavelle J. (2013). A political ecology of the Citarum river basin: Exploring "integrated water resources management" in West Java, Indonesia. Berkeley Undergraduate Journal, 26, 86-107

[35] Cita-Citarum (2013). Colourful of Citarum in Majalaya (Warna-Warni Citarum di Majalaya). Indonesia

[36] Alam F. A., Sembiring E., Muntalif B. S. \& Suendo V. (2019). Microplastic distribution in surface water and sediment river around slum and industrial area (Case study: Ciwalengke River, Majalaya district, Indonesia). Chemosphere, 224, 637-645

[37] Fatimah N. (2019). Abundance and Composition of Macroplastic and Microplastic in Estuary Water of Citarum River, Bekasi Regency, West Java province (Komposisi dan Kelimpahan Makroplastik dan Mikroplastik Pada Air Di Muara Sungai Citarum, Kabupaten Bekasi, Provinsi Jawa Barat). Bachelor Thesis, Bogor Agricultural University

[38] Fareza A. A. \& Sembiring E. (2020). Occurrence of microplastics in water, sediment and milkfish (Chanos chanos) in Citarum river downstream (Case study: Muara Gembong). E3S Web of Conferences, 148, 1-5

[39] Sembiring E., Fareza A. A., Suendo V. \& Reza M. (2020). The presence of microplastics in water, sediment, and milkfish (Chanos chanos) at the downstream area of Citarum river, Indonesia. Water, Air, and Soil Pollution, 231, $1-14$

[40] Baldwin A. K., Corsi S. R. \& Mason S. A. (2016). Plastic debris in 29 Great Lakes tributaries: relations to watershed attributes and hydrology. Environmental Science and Technology, 50, 10377-10385

[41] Ziajahromi S., Neale P. A., Rintoul L. \& Leusch F. D. L. (2017). Wastewater treatment plants as a pathway for microplastics: Development of a new approach to sample wastewater-based microplastics. Water Research, 112, 93-99

[42] Talvitie J., Mikola A., Koistinen A. \& Setälä O. (2017). Solutions to microplastic pollution - removal of microplastics from wastewater effluent with advanced wastewater treatment technologies. Water Research, 123, 401-40 